Jahrbuch für Geschichte Lateinamerikas

Anuario de Historia de América Latina

58 | $2021 \mid 171-201$

Brenda Escobar Guzmán

Universidad Industrial de Santander

Entre disputas partidistas y supervivencia La guerra de los Mil Días (Colombia 18991902)
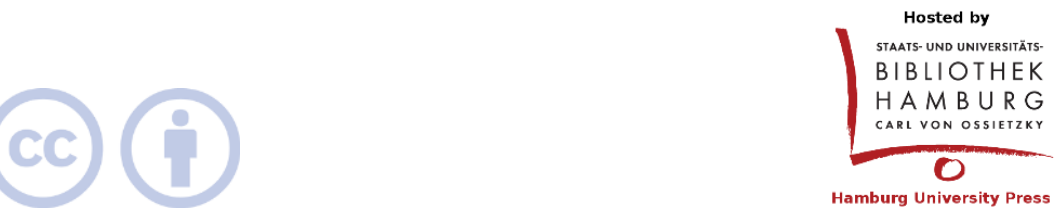

Except where otherwise noted, this article is licensed under a

Creative Commons Attribution 4.0 International license (CC BY 4.0)

https://doi.org/10.15460/jbla.58.229 


\title{
Entre disputas partidistas y supervivencia La guerra de los Mil Días (Colombia 1899-1902)
}

\author{
Brenda Escobar Guzmán ${ }^{1}$
}

Abstract. - This article argues that the ideological conflicts that set Colombian notables against each other in the 19th century can explain the discursive construction of the belligerent scene that started wars, but they do not fully explain their development. First, an overview of the 19th century political conflicts in Colombia is offered, summarizing the discussions they were based on. Subsequently, the text focuses on the last of those internal wars, the "Thousand Days' War". It aims to show that although several of the debates of transcendent order that had appeared in previous conflicts are also observed in this one, during the war these great causes lost strength and actions for mere survival generated in the heat of the armed confrontation played a more important role to define friends and enemies.

Keywords: Colombian History, 19th Century Politics, Political Parties, Civil War, Thousand Day's War.

Resumen. - El artículo intenta mostrar que los conflictos ideológicos que enfrentaron a los notables colombianos en el siglo XIX pueden explicar la construcción discursiva del ambiente belicista que daba inicio a las guerras, pero se quedan cortos para comprender su desarrollo. Primero se ofrece una panorámica de la conflictividad del siglo XIX en Colombia resumiendo las discusiones que movieron en términos generales esos conflictos. Posteriormente el texto se centra en la última de las guerras internas del período, que por su prolongada duración se denominó "de los Mil Días". Se quiere mostrar que si bien varios de los debates de orden trascendente que habían aparecido en conflictos anteriores también se observan en este, en el trascruso de la guerra se fueron debilitando estas grandes causas y jugaron un

\footnotetext{
${ }^{1}$ La autora agradece la colaboración del estudiante de Maestría en Historia de la Universidad Industrial de Santander Juan Sebastián Bonilla para poner el texto en el formato adecuado. Igualmente agradece los valiosos comentarios de los evaluadores del artículo.
} 
rol más importante las acciones por la mera supervivencia, generadas al calor del enfrentamiento armado.

Palabras clave: historia de Colombia, política siglo XIX, partidos políticos, guerra civil, guerra de los Mil Días.

Este artículo se inscribe dentro de un dossier que invita a reflexionar sobre la relación entre los conflictos ideológicos característicos del siglo XIX en los países andinos y su relación con la violencia política. El dossier se conduce a entender qué temas generaban división entre las élites y qué tanto esos temas de enfrentamiento produjeron una movilización amplia o terminaron justificando rebeliones con participación popular. Este artículo explora esta problemática revisando la guerra civil colombiana denominada de los "Mil Días": una guerra, como otras del siglo, librada entre liberales y conservadores, pero en la que el número de muertos fue particularmente alto (unos 25.000 para una población de poco más de cuatro millones de personas) ${ }^{2}$ y que se prolongó por un tiempo más largo que conflictos civiles anteriores en Colombia (y por ello la popularización de la designación de guerra de "tres años" o de "mil días"). Esta prolongación se debió en buena medida al surgimiento de grupos armados de carácter popular (denominados "guerrillas") que adquirieron autonomía con respecto a los líderes políticos que instigaron la guerra, quienes tuvieron gran dificultad para acabarla por la vía de la negociación. Por ser además leída como causa inmediata de la pérdida de Panamá, en 1903, los contemporáneos y luego los historiadores la catapultaron como el cierre ominoso de un siglo XIX marcado por la guerra y políticamente perdido.

Esta guerra civil estalló en octubre de 1899 tras un llamamiento de liberales excluidos de los puestos gubernamentales controlados por conservadores. Los liberales aducían que no había espacios de participación democrática para ellos y que sus intentos de hacer parte del juego democrático en los momentos de elecciones eran sistemáticamente controlados por los conservadores por medio del fraude. En efecto, la política para ese momento se consideraba como un

2 Adolfo Meisel, "La mortalidad de la Guerra de los Mil Días. 1899-1902": Cuadernos de Historia Económica y Empresarial, 43 (2017), pp. 1-34. El autor ofrece un sofisticado análisis demográfico para calcular esta tasa de muertos y refutar cifras de otros autores que hablan de cien mil muertos sin mucho fundamento. 
campo de ejercicio exclusivo del bando ganador y de completa exclusión del contrario. El partido que ejercía el gobierno había ascendido desde 1886 bajo una bandera bipartidista, el Partido Nacional, que en la práctica estaba excluyendo a los liberales "radicales", que habían gobernado desde 1863, y también a algunos conservadores. La Constitución instaurada en aquel año buscaba una regeneración del país, favoreciendo el modelo centralista y otorgando un poder supremo a la Iglesia católica. Con esa fórmula se contrapusieron al sistema de gobierno que reinaba desde los años 50, el cual apostaba por un régimen federal, la defensa de las libertades individuales y la separación entre asuntos políticos y eclesiásticos (con fuerte oposición de la Iglesia).

Esta dicotomía entre dos partidos con programas contrapuestos estuvo en la base de todos los conflictos civiles colombianos del siglo XIX desde 1830 y en términos generales hizo parte de la confrontación política generalizada en el mundo atlántico tras la crisis monárquica y el surgimiento del republicanismo en diferentes países europeos y latinoamericanos. ${ }^{3}$ En la denominada para ese entonces Nueva Granada, desde finales de los años 40 aparecieron los liberales, que propendían por un régimen orientado a una mayor autonomía individual, reducción del poder del Estado y un proyecto cultural no religioso. En oposición, surgieron los conservadores, que defendían la idea de un Estado fuerte, la conservación de las costumbres y la Iglesia como reguladora de la moral y la educación. Estos fueron los puntos centrales que enfrentaron ideológicamente a estos partidos, aunque en la práctica existía consenso sobre la defensa del republicanismo (constitucionalismo, división de poderes, sistema electoral representativo).

La guerra que revisaremos nació de ese mismo conflicto partidista. Pero nos interesa indagar hasta qué punto estos asuntos de la alta esfera política, que dividían a los dirigentes políticos, penetraban en otros grupos poblacionales. Aquí se argumenta que al nivel de la gente del común, la guerra se orientaba por motivos de tipo más pragmático: la guerra invadía los territorios y en ese contexto, la gente debía enrolarse en algún bando, no por una convicción ideológica, sino para mantenerse vivos.

\footnotetext{
${ }^{3}$ Hilda Sábato, Republics of the New World. The Revolutionary Political Experiment in the Nineteenth-Century Latin America, Princeton: Princeton University Press, 2018, Introducción.
} 
Para ello daremos primero un esbozo de cómo la historiografía ha explicado la conflictividad del siglo XIX colombiano y en particular la guerra de los Mil Días, mostrando que se ha dado preponderancia a la comprensión del enfrentamiento partidista. Aquí se seguirá a la historiografía que ha buscado redimensionar esos conflictos, insertándolos en el proceso más amplio de construcción del Estado moderno. Luego se trasladará el foco a la guerra de los Mil Días, para mirar tanto la discusión discursiva de los impulsores del conflicto, como la expansión del conflicto en el ámbito local, donde pudo primar la cuestión práctica de la supervivencia.

\section{Enfrentamiento partidista o construcción de Estado moderno}

Los relatos históricos del siglo XIX colombiano suelen poner el énfasis en su conflictividad. El período entre la disolución del proyecto de la gran república colombiana de Bolívar y el final de siglo se le denomina recurrentemente como la "época de las guerras civiles", 4 pues, descontando la guerra de independencia, se enumeran en ese lapso al menos ocho insurrecciones que tuvieron la pretensión de derrocar el gobierno nacional, que se extendieron por diferentes zonas del territorio y que generaron un número significativo de enfrentamientos armados y de muertes. Estas guerras se dieron en contextos geográficos específicos y varias fueron de duración corta, a veces solo de meses. En ello coinciden con la caracterización que hace Miguel Ángel Centeno de las guerras civiles latinoamericanas del XIX, a las que considera como "guerras limitadas": conflictos de corta duración, con algunos momentos de ferocidad, limitados a pequeñas zonas geográficas, que no movilizaron a grandes ejércitos. Se diferencian entonces de guerras que se estaban viviendo contemporáneamente en Europa o de la guerra civil en Estados Unidos, que fueron de alta letalidad, amplia extensión

\footnotetext{
${ }^{4}$ Álvaro Tirado Mejía, Aspectos sociales de las guerras civiles en Colombia, Medellín: Colección Autores Antioqueños, 1995, p. 10. Gonzalo España, La guerra civil de 1885. Núñez y la derrota del radicalismo, Bogotá: Áncora, 1985. Gonzalo España, El país que se hizo a tiros, Medellín: Debate, 2013. Thomas Fischer, "La constante guerra civil en Colombia": Peter Waldmann / Fernando Reinares (eds.), Sociedades en guerra civil. Conflictos violentos de Europa y América Latina, Barcelona: Paidós, 1999, pp. 255-276.
} 
geográfica y creciente implicación de la población civil. 5 Aunque estas comparaciones permiten relativizar la magnitud de estas guerras, ellas se han configurado como hitos de una narrativa que caracteriza el pasado colombiano como esencialmente violento, lo cual es útil para encuadrar en ese marco explicativo también el conflictivo presente. Por esta razón, dentro de la historiografía política colombiana, las guerras civiles del siglo XIX han tenido una presencia importante, ocupando un lugar destacado la última de ellas, la de los Mil Días. ${ }^{6}$

Siendo así, la pregunta sobre el porqué de esas guerras ha tratado de ser resuelta desde distintas corrientes historiográficas, lo que ha generado explicaciones en varios sentidos. Ha primado el tema del enfrentamiento partidista, que era el argumento utilizado por los propios actores en sus discursos y memorias, y también pasó a ser

5 Centeno realiza esta caracterización a partir de un análisis cuantitativo comparativo de los diferentes conflictos nacionales e internacionales vividos en todos los países latinoamericanos en el siglo XIX. Miguel Ángel Centeno, Sangre y deuda. Ciudades, Estado y construcción de nación en América Latina, Bogotá: Universidad Nacional de Colombia, 2014. Aun teniendo en cuenta las comparaciones de Centeno, estos ocho conflictos caben dentro de una definición amplia de "guerra civil" como la que acuña Stathis Kalyvas: "combate armado dentro de las fronteras de una entidad soberana organizada entre partes sujetas a una autoridad común al inicio de las hostilidades". Stathis Kalyvas, The Logic of Violence in Civil War, Nueva York: Cambridge University Press, 2006, p. 17. También pueden ser consideradas como guerras civiles si se usa una medida cuantitativa, por ejemplo al menos mil muertes en acciones bélicas al año. Jorge Giraldo y José Antonio Fortou recogen este tipo de datos para comparar las guerras colombianas de los siglos XIX y XX, en "Una comparación cuantitativa de las guerras civiles colombianas": Análisis Político, 72 (2011), pp. 3-21. Como otros, Michael Riekenberg señala que la cuantificación de víctimas de las guerras civiles en Latinoamérica en el siglo XIX es difícil de hacer, pero que en general la historiografía reciente ha puesto en duda la alta letalidad y los severos niveles de violencia de estas guerras. Aun con ello, Riekenberg señala que sigue siendo interesante preguntarse por los significados que les otorgaron sus protagonistas, quienes fueron los primeros en denominar esos conflictos como "guerras civiles". Michael Riekenberg, "Zur Anthropologie des Krieges in Lateinamerika im 19. Jahrhundert": Dietrich Beyrau / Michael Hochgeschwender / Dieter Langewiesche (eds.), Formen des Krieges. Von der Antike bis zur Gegenwart, Paderborn: Ferdinand Schöningh, 2007, pp. 197-201.

${ }^{6}$ Miguel Borja, "La historiografía de la guerra en Colombia durante el siglo XIX": Análisis Político, 85 (2015), pp. 173-188. 
considerado por la historiografía como el punto de roce permanente que originaba la conflictividad. ${ }^{7}$ Desde los primeros manuales de enseñanza de la historia de Colombia como el de Jesús María Henao y Gerardo Arrubla de 1910, ${ }^{8}$ se hablaba del acentuado bipartidismo del país como razón de las constantes pugnas. Con las ideas marxistas que empezaron a penetrar en las interpretaciones historiográficas en Colombia desde los años treinta, se intentó relacionar la explicación del tradicional enfrentamiento partidista con los intereses económicos en pugna de los grupos dominantes. ${ }^{9}$

La Nueva Historia de los años setenta recalcó también en el "siglo y medio de bipartidismo". Álvaro Tirado Mejía, representante de esta corriente, fue crucial en la reinterpretación de las guerras desde el enfoque de la lucha de clases: el enfrentamiento partidista secular se cruzaba con un enfrentamiento social más fundamental entre caudillos terratenientes que peleaban por tener incidencia en el reparto político y arrastraban tras de sí, gracias a sus lazos clientelistas, a una soldadesca que ignoraba los móviles de los conflictos. ${ }^{10}$ Charles Bergquist, quien ha ofrecido la interpretación más sólida y completa de la guerra de los Mil Días hasta el momento, puede incluirse dentro de esta corriente que daba centralidad al análisis económico. La tesis de Bergquist era que esta guerra había sido mirada solo desde el aspecto político, mientras para él, como era usual en la discusión académica de su tiempo, la historia política está subordinada a la historia económica y por tanto el estudio de la actividad económica del período en las

7 Jorge Orlando Melo, “Del federalismo a la Constitución de 1886“ y “La constitución de 1886“: Álvaro Tirado Mejía (ed.), Nueva Historia de Colombia, Bogotá: Editorial Planeta, 1989, pp. 17-64; Charles Bergquist, Café y conflicto en Colombia (1886-1910). La guerra de los Mil Días, sus antecedentes y consecuencias, Bogotá: El Áncora, 1999, pp. 133-159.

${ }^{8}$ Jesús María Henao / Gerardo Arrubla, Compendio de la historia de Colombia para la enseñanza en las escuelas primarias de la República, Bogotá: Voluntad, 1911.

${ }^{9}$ Alexander Betancourt, Historia y nación. Tentativas de la escritura de la historia en Colombia, Medellín: La Carreta, 2007, p. 115. Dos estudios sobre la guerra de los Mil Días pueden ubicarse en esta corriente: Gonzalo París Lozano, Guerrilleros del Tolima, Bogotá: El Áncora, 1984 (1ª edición 1937), y Joaquín Tamayo, La revolución de 1899, Bogotá: Cromos, 1938.

10 Tirado, Aspectos sociales, pp. 11-31. Sobre la longevidad del conflicto bipartidista: Tirado, "Colombia. Siglo y medio de bipartidismo": Jorge Orlando Melo (ed.), Colombia hoy, Bogotá: Banco de la República, 2001, pp. 103-178. 
regiones de conflicto (específicamente los inicios de la economía cafetera en el país) debía ser tanto o más importante que el análisis político. ${ }^{11}$

A pesar de sus distintas perspectivas, estos autores coinciden en ver esta guerra como hito notable dentro de una historia colombiana plagada de conflictos. Esta idea de un siglo XIX conectado al XX por el hilo del enfrentamiento violento entre partidos, fue afianzada por "violentólogos" como Gonzalo Sánchez, quien partía de la premisa de que Colombia había sido un país "en guerra permanente", lo cual se demostraba por el alto número de guerras en el siglo XIX, los alarmantes niveles de violencia de mediados del siglo XX (período denominado "La Violencia") y un conflicto no cerrado en el momento en que escribía. ${ }^{12}$ Específicamente sobre la guerra de los Mil Días, Sánchez ha enfatizado en el hecho de que no solo fue la última del siglo XIX, sino también la primera del XX, en cuanto tuvo eco en la dinámica bipartidista y sectaria de La Violencia de los años cincuenta.

Fernán González contribuye a complejizar la comprensión del fenómeno yendo más allá de una explicación monocausal y fatalista de constante y ciego enfrentamiento partidista, al dar énfasis a su vinculación con las coyunturas específicas en que se dieron y, en esa medida, como respuesta a discusiones de tipo político que se avanzaban

11 Bergquist, Café y conflicto. Recuérdese que este libro fue primero una tesis doctoral defendida en 1973 en Stanford y en 1981 fue publicada por primera vez en español. Ver especialmente el prólogo y el prefacio a la segunda edición en inglés en pp. 16-18, 22-28.

12 Gonzalo Sánchez, "Los estudios sobre la violencia. A. Balance y perspectivas": Gonzalo Sánchez / Ricardo Peñaranda (eds.), Pasado y presente de la violencia en Colombia, Bogotá: Cerec, 1991, p. 19. Críticas al fatalismo de ese relato se encuentran por ejemplo en Eduardo Posada Carbó, La nación soñada. Violencia, liberalismo y democracia en Colombia, Bogotá: Norma, 2006. También Centeno, Sangre y deuda, pp. 23-67. Debe indicarse que Sánchez ha complejizado posteriormente su mirada del pasado colombiano como esencialmente guerrero y ha hecho aportes, al menos en su papel de editor, para incluir aspectos de orden más cultural al análisis de la guerra, que incluyen otros actores como mujeres, artistas, clero, grupos populares, vistos no solo desde la discusión política, sino también desde la vivencia más cotidiana de la guerra. Ver por ejemplo Gonzalo Sánchez / Mario Aguilera (eds.), Memoria de un país en guerra. Los Mil Días 1899-1902, Bogotá: Planeta, 2001, Introducción. 
no solo en el nivel nacional sino transnacional.13 Esto es particularmente observable en dos grandes discusiones que hacen parte de la configuración de un Estado moderno y, en últimas, del nacimiento del mundo global moderno al que la realidad latinoamericana obviamente no fue ajena. ${ }^{14}$ De un lado, aparecen los debates sobre la adopción de formas republicanas para gobernar los Estados. Los países latinoamericanos recién independizados de las metrópolis europeas fueron pioneros en abandonar el modelo monárquico y en instaurar gobiernos asumidos por los ciudadanos, pero la definición de esa "ciudadanía" fue generadora de intensos y aun sangrientos debates. ${ }^{15}$ Por el mismo camino, la idea de Estado se había venido secularizando. En el contexto de las antiguas colonias hispanoamericanas, esto llevó a los intentos de reducción del poder que tradicionalmente había detentado la Iglesia católica, pero también a la intensa lucha de esta institución por preservarlo, lo cual en nuestro contexto se reflejó en profundos debates que degeneraron a veces en guerras.

Miremos cómo aparecieron esas dos grandes discusiones en las distintas guerras del siglo XIX colombiano. El asunto sobre quiénes de los miembros de la población eran los facultados para hacer parte de la ciudadanía política estuvo en la base de la guerra de 1839, la primera de las guerras después de la ruptura de la Gran Colombia. En la década del 1850 volvió el conflicto armado, muy conectado al ciclo de revoluciones de mediados de siglo en varios países europeos. La revolución que llevó a la instauración de la Segunda República Francesa en 1848 inspiró con su vocabulario a los líderes políticos de la Nueva Granada, quienes redactaron sendas declaraciones de principios para esclarecer la posición ideológica de los ahora abiertamente

13 Fernán González, Partidos, guerras e Iglesia en la construcción del Estado Nación en Colombia (1830-1900), Medellín: La Carreta, 2006.

14 Para observar este fenómeno de la creciente globalización del mundo desde el siglo XIX resulta fundamental el libro de Jürgen Osterhammel, Die Verwandlung der Welt. Eine Geschichte des 19. Jahrhunderts, München: Beck, 2009. Existe una traducción al español: La transformación del mundo. Una historia global del siglo XIX, Barcelona: Planeta, 2015. El autor puntualiza algunas características globales del siglo XIX (después de problematizar su periodización) en el acápite II.4.

15 Recientemente H. Sábato ofreció un magistral análisis de este proceso comparando varios países latinoamericanos. Sábato, Republics, pp. 22-49 especialmente. 
denominados Partido Liberal y Partido Conservador. Como dijimos, mientras los primeros decían propender por un gobierno más democrático, una mayor autonomía local, una disminución del poder de la Iglesia y una apertura del poder político a sectores más amplios de la sociedad, los segundos desconfiaban de una toma popular del poder y expresaban los riesgos que podría generar la inclusión de población analfabeta en el cuerpo político "sin que pasaran por el tamiz de la civilización y educación de acuerdo a los valores morales del cristianismo". 16

Este enfrentamiento político transmutó en enfrentamientos guerreros variados: la guerra del 1851 tuvo como trasfondo un discurso exaltado de miedo a la ampliación del cuerpo político (debido a la abolición de la esclavitud y a la adopción, efímera, del sufragio universal) y los peligros de que el pueblo raso llevara el país al jacobinismo. ${ }^{17} \mathrm{El}$ empoderamiento popular hizo que los que antes habían propendido por la ampliación ciudadana, la vieran ahora como un peligro. Ello llevó a una nueva guerra civil en 1854 en la que una coalición de los notables de ambos partidos se unió para sacar a esas fuerzas populares del poder y retomar así su tradicional hegemonía. ${ }^{18}$

El debate de la guerra del 1859 fue por el grado de incidencia que podía tener el centro político en los asuntos de los estados confederados, sistema instaurado desde 1857 obedeciendo a la idea en boga en diferentes países latinoamericanos en ese momento, de las ventajas de la descentralización y la disminución del poder del estado. $\mathrm{Su}$ resultado fue la consolidación de un sistema federal que concedía amplia autonomía a los estados federados, y un papel muy débil al estado central, régimen que perduró hasta 1885, cuando nuevas circunstancias mundiales inclinaron también la situación localmente, como veremos.

\footnotetext{
16 González, Partidos, pp. 25; 51.

17 Fernán González, "El mito antijacobino como clave de lectura de la Revolución Francesa": Para leer la política, Bogotá: CINEP, 1997 (tomo 2), pp. 163-188. Fabio Zambrano, "El miedo al pueblo. Contradicciones del sistema político colombiano": Análisis. Conflicto social y violencia en Colombia. Documentos ocasionales, 53 (1989), pp. 13-18. Laura Quintana Porras, "Ezequiel Rojas y la moral utilitarista": Rubén Sierra Mejía (ed.), El radicalismo colombiano del siglo XIX, Bogotá: Universidad Nacional de Colombia, 2008, pp. 11-38.

18 González, Partidos, pp. 57-68.
} 
Además del tema de las formas de organización del sistema republicano, la otra gran cuestión de disputa fue el rol que debía asumir la Iglesia católica en ese orden republicano, en tanto el mundo se iba desacralizando y la Iglesia, también en Europa, vio amenazada su tradicional función política, mientras se pretendía relegar lo religioso al ámbito de lo privado. Así como en Europa y en los nacientes países latinoamericanos, en Colombia hubo adeptos del anticlericalismo y la secularización, y se intentó dividir la esfera de lo público y lo privado tratando de excluir a la religión de la primera y dar un carácter meramente privado a la experiencia religiosa; pero también se vivió la vehemente reacción de la Iglesia y sus seguidores en apoyo de la romanización y el ultramontanismo. ${ }^{19}$

De allí que este proceso generara divisiones políticas que llevaron también a conflictos violentos. Como lo ha indicado la historiografía, en Colombia este fue el punto que marcó la separación clara de los partidos conservador y liberal, más que su concepción política: la agenda republicana fue defendida por ambos; también terminaron coincidiendo, aunque con distintos argumentos, en que la ampliación de los derechos de ciudadanía a toda la población era peligrosa; y el proyecto económico no fue muy diferente. Fue la relación con la Iglesia la que generó el principal distanciamiento ideológico. ${ }^{20}$ El partido conservador desde su nacimiento se planteó como un partido en defensa de las instituciones tradicionales y de una identidad fuerte heredada de siglos basada en las creencias de la religión católica. El liberalismo, por su parte, se manifestó como doctrina que propendía por la separación entre poder político y religión. Aunque no eran principios excluyentes, en la práctica sí fueron usados para la exclusión del otro y en todas las guerras posteriores a la creación de los partidos

19 Gustavo Arce, De espaldas a Cristo. Una historia del anticlericalismo en Colombia. 1849-1948, Medellín: Universidad de Antioquia, 2018; José David Cortés, La batalla de los siglos. Estado, Iglesia y religión en Colombia en el siglo XIX. De la independencia a la regeneración, Bogotá: Universidad Nacional, 2016, pp. 15-19.

20 Sobre el tema deben citarse a Fernán González, Poderes enfrentados. Iglesia y Estado en Colombia, Bogotá: CINEP, 1997; Luis Javier Ortiz, Obispos, clérigos y fieles en pie de guerra. Antioquia. 1870-1880, Medellín: Universidad Nacional de Colombia, 2010; Cortés, La batalla de los siglos. Para entender cómo se dio el estratégico acercamiento de los conservadores a las autoridades eclesiásticas resulta interesante el relato de Máximo Nieto, Recuerdos de la regeneración, Bogotá: Casa Editorial Marconi, 1924. 
apareció esta como una causa tanto para ganar amigos como para construir enemigos. Fue raíz de debate político y también de conflicto armado si la educación, como gran pilar de la ciudadanía moderna, podía ser controlada por organizaciones religiosas como los jesuitas (reformas constitucionales de 1843 y 1857) o si debía ser laica (motivo central de la guerra de 1876). Pero también el poder temporal que podía tener la Iglesia (por ejemplo como administradora de bienes y tierras) o la relación de poder entre el Estado y la Iglesia (si el Estado podía intervenir o no en temas de elección de arzobispos y sacerdotes, si podía haber un fuero eclesiástico distinto al civil), asuntos que fueron también motivadores de la guerra de 1876 y argumentos para la del 1885. A finales de siglo esta discusión se decantó hacia el fortalecimiento del papel de la Iglesia, a la cual el gobierno concedió amplios poderes tanto en lo político, como en lo económico y lo educacional.

Este giro de favorabilidad hacia el protagonismo político de la Iglesia de finales de siglo XIX coincide con un cambio de percepción sobre el poder de la ciudadanía. Incluso dentro del liberalismo fue surgiendo un sector (los independientes), que si bien antes habían propendido por mayor democratización y descentralización política, tendieron a defender ahora gobiernos más autoritarios, más centralizados, que dieran menos juego político a la ciudadanía. Tal fortalecimiento del gobierno central no era ajeno al contexto latinoamericano de finales de siglo. El lema de gobierno de Porfirio Díaz de "poca política y mucha administración", sumado a una reducción del juego electoral y una perpetuación suya en el mando presidencial, se veían como un modelo exitoso de gobierno en su tiempo. ${ }^{21} \mathrm{Y}$ es interesante observar que en otros contextos podía encontrarse una tendencia similar. Según Osterhammel, después de un tiempo de revueltas constantes en las décadas medias del siglo, hacia su final varios países fueron consolidando un orden político más fuerte y estable (se refiere a contextos tan distintos como Alemania, Estados Unidos, México, Siam o China). Para este autor, tal fenómeno puede leerse en términos negativos como reforzamiento de los aparatos estatales, pero también en términos positivos como una recuperación de la capacidad de

21 Adriana María Suárez Mayorga, "La construcción de la nación colombiana a la luz del modelo porfirista": Secuencia, 98 (2017), pp. 99-129. 
negociación de los estados y un mayor interés de estos por conservar la paz. ${ }^{22}$

A ello se unía una economía mundial cada vez más orientada a los intercambios comerciales internacionales. Osterhammel habla de la interconexión de empresas de los países cada vez más industrializados con mercados internacionales donde se empezaban a transformar los hábitos de consumo. ${ }^{23}$ Tulio Halperín, en su síntesis de la historia latinoamericana, describe este período (hasta la Primera Guerra Mundial) como un tiempo de "madurez del orden neocolonial"; 24 Marcello Carmagnani lo denomina "Edad de Oro del proyecto oligárquico". ${ }^{25}$ Se refieren a la toma de poder nacional por parte de una clase política que tenía intereses empresariales y comerciantes y buscaba mercantilizar sus productos internacionalmente. La coincidencia entre intereses económicos y políticos propició estabilidad en ambos ámbitos. Así, para finales de siglo se propendió por estados fuertes, gobernados por profesionales capaces de llevar a cabo proyectos de infraestructura y economía moderna, cimentados en argumentos técnicos y dejando a un lado las discusiones meramente ideológicas y partidistas. Era el orden el que garantizaría las bases para el progreso.

El contexto nacional no fue ajeno a esa tendencia. Con la guerra de 1885 y la Constitución de 1886 se entronizó un grupo de poder que combinaba liberalismo económico con pragmatismo político. Se hizo fuerte la idea de la necesidad de una "Regeneración" del estado por medio de un gobierno centralizado y fuerte, que impulsara los proyectos económicos, para lo cual no se necesitaba dar mucho espacio a la ciudadanía. También con el afán de crear un ambiente menos conflictivo, se zanjó la discusión sobre el poder de la Iglesia otorgándole un papel mayúsculo en el manejo de la educación, la cultura y la moral.

22 Osterhammel, Die Verwandlung, pp. 112-113.

23 Osterhammel, Die Verwandlung, pp. 111-112.

24 Así titula Halperín el acápite dedicado al período de finales del siglo XIX y comienzos del XX. Historia contemporánea de América Latina, Madrid: Alianza, 1969, pp. 280-358.

25 Es el título del capítulo en que Marcello Carmagnani estudia este mismo período en Estado y sociedad en América Latina. 1850-1930, Barcelona: Crítica, 1984, pp. 98-175. 
Esto no se dio sin oposición. Los levantamientos de finales de siglo se manifestaron contra un gobierno que bajo el supuesto de haber sido llevado al poder por un Partido Nacional, combinación de fuerzas conservadoras y liberales (al menos del sector independiente), pretendía representar a los actores políticos principales y por ello dejaba poco juego a la oposición. La rebelión del 1895 tuvo corta duración y alcances, pero la del 1899 estuvo mejor organizada y apertrechada, y terminó siendo la más duradera de las guerras civiles del siglo XIX.

En ella se observaron en juego varios de los problemas del proceso de construcción de estado moderno, no distantes de lo vivido en otros momentos del siglo tanto en el país como en la región y otras zonas del mundo: el fortalecimiento de un poder central, la negociación del poder central con los poderes regionales, el creciente poder político ganado por la población, y el debate entre el poder de la Iglesia y el poder secular. ${ }^{26}$ La guerra de los Mil Días ejemplifica cómo esos enfrentamientos solían pasar de los espacios de la discusión legislativa y administrativa a la lucha armada, lo cual para el siglo XIX era visto como forma válida (aunque trágica) de hacer política, como lo expresó Clausewitz y como puede observarse en declaraciones de los líderes políticos que participaron en las guerras. ${ }^{27}$

\section{Discursos en disputa a finales del siglo}

Habiendo observado cómo en las guerras civiles del XIX las controversias entre las diferentes posturas sobre la configuración estatal pasaban del orden político al militar y viceversa, veamos las discusiones que enfrentaron verbal y luego armadamente a los líderes de los partidos a finales del siglo.

26 Fernán González, Poder y violencia en Colombia, Bogotá: CINEP, 2016, pp. 186-217.

27 Ver por ejemplo Aníbal Galindo, Recuerdos históricos, Bogotá: Imprenta de la Luz, 1903; Rafael Uribe Uribe, Documentos militares y políticos, Bogotá: Imprenta de Vapor, 1904; José María Vesga y Ávila, La guerra de los Tres Años, Bogotá: Imprenta Eléctrica, 1914. Karl von Clausewitz, Vom Kriege, Erstes Buch, 2010 (1832), en línea: https://www.clausewitz-gesellschaft.de/wp-content/uploads/ 2014/12/VomKriege-a4.pdf [02-11-2021]. 
Para iniciar, pueden mencionarse unas características del discurso liberal compartidas a nivel internacional, sobre las que Carlos Eduardo Jaramillo ha hecho anotaciones interesantes, que estamos en mora de estudiar mejor. ${ }^{28}$ Sostiene que para finales de siglo podría hablarse de una "internacional liberal" que compartía ideologías múltiples: masonería, gnosticismo, espiritismo, socialismo, librepensamiento. Sin embargo, el mismo historiador advierte que es difícil referirse a esa base de entendimiento como una agrupación homogénea de intelectuales, políticos y militares, sino que

"reviste más el carácter de una corriente renovadora del pensamiento donde tenía cabida la más variada gama de actitudes y criterios que edificó una solidaridad entre la clase dirigente latinoamericana". ${ }^{29}$

Entre los miembros de esa clase dominante, Jaramillo cita a los entonces presidentes de Ecuador (Eloy Alfaro), Venezuela (Cipriano Castro) y Nicaragua (José Santos Celaya), con quienes el principal instigador de la rebelión liberal, Rafael Uribe Uribe, tuvo una activa comunicación antes de la guerra. ${ }^{30}$ Estos contactos le fueron de utilidad para la consecución de algún financiamiento y armas, aunque esta colaboración no fue en las magnitudes soñadas, porque esos mandatarios también eran observados internamente por sus enemigos políticos y porque la administración de sus propios países no daba siempre la posibilidad de ayudar a amigos externos. Además, se corría el riesgo de poner en peligro las relaciones diplomáticas con Colombia y de ser catalogados como invasores de la soberanía colombiana. ${ }^{31}$ Por demás, ¿era tan fuerte el compromiso con la expansión de la ideología liberal a nivel continental? Como quiera que fuese, el punto que quiere señalarse aquí es que el posible ecumenismo liberal que sugiere Carlos Jaramillo no era

28 Carlos Eduardo Jaramillo, Los guerrilleros del novecientos, Bogotá: Cerec, 1991, pp. 279-282. Ver también Thomas Fischer, "De la guerra de los Mil Días a la pérdida de Panamá": Gonzalo Sánchez / Mario Aguilera (eds.), Memoria de un país en guerra, pp. 75-104.

29 Jaramillo, Los guerrilleros, p. 280.

30 Uribe Uribe incluso hizo un viaje en 1897 que empezó en el Cauca, continuó en Ecuador, y posteriormente pasó por Panamá, Nicaragua y Guatemala, buscando, con poco éxito, apoyo para la guerra. Ver Vincent Baillie Dunlap, Rafael Uribe Uribe y el liberalismo colombiano, Bogotá: Universidad Externado, 2010, pp. 123-126.

31 Jaramillo, Los guerrilleros, pp. 282-300. 
un argumento de utilidad para movilizar seguidores, exceptuando ciertos círculos intelectuales muy cerrados. Las causas del librepensamiento, el gnosticismo o la masonería, e incluso el socialismo no eran ideologías de tipo popular para ese momento, de hecho eran rarezas cosmopolitas, ajenas al mundo campesino y popular.

Se ha planteado que los levantamientos del siglo XIX en los diferentes países de América Latina solían tener como impulso la implementación o restauración de los valores republicanos, no la exigencia de cambios sociales o económicos, que se constituyó en el siglo XX en el principal reclamo de nuevos grupos sociales aparecidos con la industrialización y la urbanización. ${ }^{32}$ Esto se observa bien en Colombia. Específicamente una inclinación por la defensa de las clases populares y cierto interés por el socialismo manifestado por el discurso liberal fue un fenómeno de los años iniciales del siglo XX. Fue de hecho a consecuencia de la derrota de los liberales, que tuvieron que plantear una renovación de su ideario en tanto la guerra dejó traslucir un partido y un programa en decadencia. ${ }^{33}$

El levantamiento de 1899 no se realizó en medio de un ambiente de ideales tan trascendentes como los de los años cincuenta en torno a la abolición de la esclavitud o a la universalización del sufragio, tampoco estaba en juego un tema tan espinoso como la intervención de la Iglesia católica en la educación pública, como había pasado en 1876. Incluso el argumento religioso no fue esgrimido por los instigadores de esta rebelión. Desde los años 90, muchos liberales y la dirección del partido habían comenzado a aceptar el régimen reinante, a acoplarse al centralismo y a restar interés al asunto de la división entre Estado e Iglesia. ${ }^{34}$ Lo que levantaba resquemor para ese momento eran los poderes extraordinarios de que gozaba la figura presidencial y ligado a ello, la poca participación que los liberales lograban tener en los cargos

32 Carlos Malamud, Historia de América, Madrid: Alianza, 2005, p. 376.

33 Rafael Uribe Uribe emitió en 1904 un discurso de gran difusión titulado "Socialismo de Estado", en el que planteaba la necesidad de que el liberalismo colombiano se dejara afectar por los cambios sociales, económicos e intelectuales que se observaban en el mundo y orientara su ideología hacia causas sociales, aunque expresamente negaba ser partidario de un socialismo "de abajo para arriba" que atacara la propiedad, el capital, la religión y el régimen legal. Un análisis de este discurso en Baillie Dunlap, Rafael Uribe Uribe, pp. 209-220.

34 Baillie Dunlap, Rafael Uribe Uribe, p. 99, 119. 
gubernamentales departamentales y locales, pues el presidente (cuyo período duraba seis años) tenía la potestad de la designación de los gobernadores departamentales, que a su vez ejercían control sobre los puestos burocráticos a nivel local. De esta manera, a los liberales se les excluía del juego político, pero también del manejo del presupuesto. En esa queja los acompañaba un sector del conservatismo, los "históricos", quienes por desacuerdo con la agenda económica y con la selección de los principales cargos de la administración pública, se habían alejado del gobierno, al mando de los conservadores "nacionalistas", y en continuas ocasiones manifestaron una posición favorable al descontento de los liberales. ${ }^{35}$

En las elecciones de 1898 volvió a quedar elegido para los siguientes seis años como presidente el representante del Partido Nacional, aunque su fórmula vicepresidencial pertenecía al bando de los históricos. Esta elección, como solía suceder, fue impugnada por el partido liberal como fraudulenta. Sin embargo, ni la exclusión ni el fraude eran formas nuevas del manejo político: desde la época de gobiernos liberales, la política se venía entendiendo como un ejercicio de negación política del contrario, también recurriendo de manera sistemática al fraude. ${ }^{36}$ Esta falta de legitimidad del juego democrático dificultaba llegar a acuerdos entre partidos por la vía política y daba argumentos para el llamamiento constante al enfrentamiento armado.

35 La defensa de los liberales a su decisión de emprender una guerra, según se justificaban posteriormente, se basó en este apoyo que creyeron tener de la facción de los históricos, pero estos, ya iniciada la guerra, tomaron partido por el gobierno, con quienes tenían más afinidad ideológica por tradición. Este argumento se constituyó en un punto repetido en relatos exculpatorios de diversos líderes liberales tras la guerra. Ver por ejemplo Uribe, Documentos militares, pp. xi-xxxix; Justo L. Durán, La revolución del 99, Cúcuta: El Día, 1920, Vesga y Ávila, La guerra de los Tres Años, pp. 75-91; Lucas Caballero, Memorias de la guerra de los Mil Días, Bogotá: El Áncora, 1980 (1ª edición 1938).

36 Rafael Núñez criticaba esa forma excluyente de entender la política de sus contemporáneos y planteaba como solución la idea de un "partido nacional" que unificara intereses de ambos partidos. Dichas ideas se encuentran por ejemplo en su artículo "La paz científica" de 1882, en: Rafael Núñez, La reforma política en Colombia, Bogotá: Biblioteca Popular de Cultura Colombiana, 1945 (Tomo 1), pp. 93-98. Helen Delpar estudia esta forma de entender la política en la época federal en: Rojos contra azules. El Partido liberal en la política colombiana, Bogotá: Procultura, 1994. 
En 1898, el fraude electoral, real o supuesto, sirvió de argumento para encender los ánimos. El gran azuzador de esa campaña fue Rafael Uribe Uribe, quien poco después de las elecciones pronunció un discurso, ampliamente divulgado, en el que llamaba a desobedecer los lineamientos del Directorio del partido Liberal y enfrentarse armadamente al partido en el gobierno, para no "revalidar con nuestra definitiva aprobación, el triunfo fraudulento de los usurpadores de nuestros derechos". ${ }^{37}$ Para Uribe, la opción de permanecer confiados en la discusión política pacífica, como ordenaba el Directorio del liberalismo, era refrendar el fraude del partido en el poder.

En ese mismo año, como único representante a la Cámara liberal en un congreso en su totalidad compuesto por conservadores, Uribe Uribe expresaba en otros términos, lo dispuestos que estaban él y sus seguidores para traspasar esa delgada línea entre la política y la guerra:

"venimos hoy a deciros por última vez que nos deis libertad para exponer y defender nuestro derecho con el voto, con la pluma y con los labios; de lo contrario, nadie en el mundo tendrá poder bastante para impedir que tengan la palabra los cañones de nuestros fusiles". 38

Este tipo de argumentos solían ir acompañados con la idea del republicanismo versus el despotismo, que daba más trascendencia a la opción belicista. Así puede observarse en este relato posterior a la guerra, de 1904, en que los liberales justificaban el haber optado por la vía bélica. El relato ubicaba el origen de la guerra en 1886: el triunfo de la Regeneración había hecho que quedaran "reducidos a la nada los derechos políticos del Partido Liberal". Especialmente la queja se centraba en la falta de una representación auténtica del partido en las cámaras legislativas y en el silencio que se había impuesto a las ideas liberales. El "yugo del despotismo" gubernamental que había

\footnotetext{
${ }^{37}$ Rafael Uribe Uribe, “Censura de la política liberal”, 1898. Citado en Baillie Dunlap, Rafael Uribe Uribe, p. 127.

38 Citado en La guerra en el Tolima. 1899-1903. Apuntes, documentos y relaciones de campaña recopilados por 'El Comercio' de Bogotá, Bogotá: Imprenta de Vapor, 1904, p. x. Este tipo de discursos del bando belicista tuvieron amplia difusión por medio del periódico El Autonomista, dirigido por Uribe Uribe.
} 
implantado un "absolutismo político" había cerrado toda posibilidad distinta a la guerra. ${ }^{39}$

Así, por medio del discurso, se lograba hacer de un tema de orden más práctico que ideológico, el acceso o exclusión de los puestos públicos, ${ }^{40}$ un asunto de defensa de los derechos políticos, de la representación, de la expresión, en contra del absolutismo y del despotismo. María Teresa Uribe, estudiando guerras civiles anteriores, plantea la existencia de una retórica que se repetía en cada momento prebélico. ${ }^{41}$ Se pintaba al gobierno como un tirano que estaba cerrado a toda discusión política. Por su parte, el gobierno sospechaba de cualquier reunión política, a la que tildaba de conspiración. Ello llevaba a control y represión gubernamentales, por lo que las quejas sobre comportamientos dictatoriales del gobierno se hacían realidad. Del lado liberal se solía hacer el recuento de la represión y cierre de periódicos y el destierro de líderes que estaban supuestamente planeando guerras. Periódicos y reuniones servían efectivamente para conspirar. La guerra del 1895 y la del 1899 muestran que sí había un doble propósito en estas empresas políticas y que la intención de hacer política iba muy de la mano con la intención de organizar levantamientos. Pero ellos se

39 "La guerra de 1899", p. viii. Reconstrucciones similares en Uribe Uribe, Documentos militares y políticos, pp. v-xlv; Vesga y Ávila, La guerra de los Tres Años, pp. 31-35

40 Charles Bergquist ofrece un análisis sociológico mirando edades, ocupación y origen de liberales belicistas y pacifistas y encuentra que los promotores de la guerra fueron especialmente jóvenes liberales que habían tenido poca opción de participar en las instancias centrales de decisión y manejo presupuestal, pues estas habían estado dominadas por los líderes de la Regeneración. En cambio, la Dirección liberal, controlada por hombres de mayor edad, mantenían una posición pacifista, pues ya habían tenido, en sus años de juventud y adultez política, un rol de poder en tanto el gobierno había estado dominado por ellos hasta 1885. Los jóvenes confrontaban la pasividad de los líderes tradicionales del partido, que no habían propuesto un programa nuevo después de la caída en desgracia de la federación. Pero los jóvenes tampoco tenían una agenda novedosa y planteaban la guerra como única vía para ganar un espacio político. Bergquist, Café y conflicto, pp. 145-153. Ver también Eduardo Rodríguez Piñeres, Diez años de política liberal. 1892-1902, Bogotá: Incunables, 1985 (1a edición: 1945).

41 María Teresa Uribe, "Las guerras por la nación en el siglo XIX”: Estudios Políticos, 18 (2001), pp. 8-27. Un análisis más detallado se encuentra en María Teresa Uribe / Liliana López Lopera, Las palabras de la guerra. Un estudio sobre las memorias de las guerras civiles en Colombia, Medellín: La Carreta, 2006. 
pintaban como mártires de ese gobierno dictatorial. De esa manera, hacían más fácil de comprender el sentimiento belicista y de difundir el llamado a las pasiones.

Las descripciones de las intenciones perversas de los contrarios generaban sin duda identidad, compromiso, y eventualmente movilización. Esto, unido al firme partidismo de algunos jóvenes, podía sumar un número importante de entusiastas que se enrolaban por convicción. Aquí es pertinente indicar que esto pasaba especialmente en el ámbito de algunas ciudades, más que en el campo. Nos queda una emotiva descripción de uno de estos entusiastas, Max Grillo, que se enroló en los ejércitos liberales por su compromiso con el partido. Grillo hizo un relato novelado de su experiencia en la guerra, que pasa de la fascinación inicial por la causa de la rebelión a una paulatina desilusión por los horrores que fue viviendo en la campaña guerrera. ${ }^{42}$

\section{De las discusiones políticas a la movilización para la guerra}

Se han repasado las razones principales aducidas por los liberales para hacer la guerra, indicando que tuvo mucho peso el asunto de la participación política, que ellos describían de manera más amplia como necesaria defensa del juego democrático. Si decíamos que la guerra era vista por los líderes de figuración regional o nacional que la impulsaban como prolongación de la política, ¿generaba este mismo sentimiento en la gente del común, que era quienes tenían que enfrentarse cuerpo a cuerpo en la guerra? ¿Cómo solucionar el problema práctico de conseguir hombres para tomar las armas por cuestiones políticas y que poblaciones enteras se convirtieran en "sociedades guerreras"? ${ }^{43}$ En

42 Max Grillo, Emociones de la guerra. Apuntes tomados durante la campaña del norte en la guerra civil de tres años, Bogotá: Incunables, 1984 (1a edición: 1903). Otras descripciones de los sentimientos y las vivencias cotidianas en la guerra se encuentran en los relatos compilados en el libro La guerra en el Tolima 1899. 1903, ya citado, y, en versión literaria, en la colección de cuentos de 1901 titulada El Recluta (sin editor), Medellín: Ediciones EAFIT, 2000 (1ª edición: 1901).

43 Este concepto de Alejandro Rabinovich permite ver que las guerras civiles del XIX en América Latina tenían implicaciones más allá del mero enfrentamiento armado, pues terminaban incidiendo en la vida cotidiana de la sociedad en su conjunto. Alejandro Rabinovich, "La société guerrière. Pratiques, discours et valeurs militaires au Rio de la Plata 1806-1852": Nuevo mundo mundos nuevos, (2010), pp. 1-9. 
este apartado se mirará cómo esas discusiones sobre participación política fueron expuestas y difundidas para conseguir la movilización de las personas del común para unirse a la guerra, pero también cómo otro tipo de razones entraba en juego al momento propiamente de la toma de las armas y de los enfrentamientos.

Dejemos claro que para esta época el sufragio era restringido. La Constitución de 1886 había establecido el sufragio indirecto y el requerimiento de propiedad y alfabetismo para los votantes. Estas medidas no eran muy distintas a las de varios de los estados del régimen federal liberal anterior que tuvieron restricciones de alfabetismo, ${ }^{44}$ lo cual revelaba un miedo compartido por dirigentes de ambos partidos en distintas regiones a que la gente del común tomara efectivamente el poder. ${ }^{45}$ Pero no fue una discusión de esta época, como sí lo había sido a mediados de siglo, el asunto sobre la ampliación de la ciudadanía por medio de la disminución de las exigencias para votar. Lo que se exigía eran garantías para que los liberales también pudieran hacer parte de los puestos de gobierno, así fueran nombrados por el ejecutivo.

Ahora bien, la renovación historiográfica que ha sufrido el estudio de la política del siglo XIX ha contribuido a comprender de manera más amplia la noción de participación política. Específicamente sobre las elecciones, múltiples estudios han mostrado que estas movilizaban a sectores amplios de la población, aunque muchos no pudieran votar. ${ }^{46}$ Se ha descrito bien cómo durante los períodos electorales (que incluían la previa organización de comités electorales, designación de jueces electorales, inscripción de electores, las propias elecciones, el escrutinio, el anuncio de los resultados locales y nacionales) los partidarios de los distintos candidatos generaban un clima de zozobra. Posteriormente estaban también prestos a celebrar o a impugnar

44 Aunque cuatro de los nueve estados que formaban los Estados Unidos de Colombia mantuvieron hasta el 1886 el sufragio universal masculino: Bolívar, Cauca, Magdalena y Panamá.

45 González, Partidos, pp. 57-63; Zambrano, "El miedo".

46 Un buen balance de trabajos sobre el tema electoral a nivel latinoamericano es el de Marta Irurozqui, La ciudadanía en debate en América Latina. Discusiones historiográficas y una propuesta teórica sobre el valor público de la infracción electoral, Lima: Instituto de Estudios Peruanos, 2004 (Documento de trabajo 139), pp. 7-33. Ver también Federica Morelli, "Entre el antiguo y el nuevo régimen. La historia política hispanoamericana del siglo XIX”: Historia Crítica, 33 (2007), pp. 132-137. Más reciente Sábato, Republics, pp. 50-88. 
ruidosamente los resultados. A nivel local, se dependía del partido ganador para acceder a empleos o a la protección policial o judicial. Así, las elecciones generaban un ambiente de tensión y eventual malestar social que se prestaba para captar adeptos para un levantamiento o una guerra de más envergadura. ${ }^{47}$

En un ambiente caldeado podían tener mucha efectividad palabras incendiarias como las de la retórica de Uribe Uribe. Aquí de nuevo apartes del discurso que citábamos antes, emitido poco después de las elecciones de 1898, que habían dado de nuevo el triunfo al candidato que apoyaba el gobierno:

"Nuestra disciplina bajo la represión de la Regeneración me parece como la obediencia de las cuadrillas de esclavos bajo el látigo del capataz [...] [i]no es la muerte preferible a la pérdida del honor y la dignidad?".

Al mismo tiempo criticaba la posición de los pacifistas: "Ya no es sangre sino suero perezoso y descolorido el que circula por las venas de los liberales". Discursos como estos podían tener un amplio alcance y convertir un asunto de participación electoral en un llamamiento a sentimientos generalizados como la defensa de la honra y aun de la hombría. 48

47 Malcolm Deas estudiando la guerra de 1895 indica que el fraude no solo deslegitimaba los resultados de la elección, sino que humillaba, y eso terminaba por mover a los vencidos a la reacción y al levantamiento armado. Tal situación era más acuciante en los pueblos. Ver Malcolm Deas, "Sobre la paz en el siglo XIX, con un examen particular de cómo terminaron las guerras de 1885 y 1895": Carlos Camacho / Margarita Garrido / Daniel Gutiérrez (eds.), Paz en la República. Colombia. Siglo XIX, Bogotá: Universidad Externado, 2018, pp. 265-266. Charles Bergquist llamaba la atención también sobre este punto estudiando los antecedentes de la guerra de los Mil Días. Bergquist, Café y conflicto, pp. 153-159. Sigue siendo muy útil para entender la vida política local: Malcolm Deas, Del poder y la gramática y otros ensayos sobre historia, política y literatura colombianas, Bogotá: Tercer Mundo, pp. 175-206. Para analizar las elecciones previas a la guerra de los Mil Días es muy rico el archivo personal del director del partido liberal Aquileo Parra, conservado en el Archivo General de la Nación, Fondo Academia Colombiana de Historia, caja 4. También el análisis ya citado de Rodríguez Piñeres, Diez años de política liberal.

48 Citas del discurso de Uribe Uribe, "Censura de la política liberal", citado en Baillie Dunlap, Rafael Uribe Uribe, pp. 127-128. Baillie Dunlap muestra a partir de análisis de prensa y correspondencia cómo este discurso tuvo una amplia acogida 
Los gobiernistas también tuvieron que generar sentimientos belicistas para tener apoyo a su causa. En su caso, fue frecuente recurrir a la equiparación del conflicto liberal-conservador con una guerra santa. Esto a pesar de que los rebeldes liberales, como dijimos, no adujeron como razón de su levantamiento la idea de debilitar el poder de la Iglesia, ni se debatía con fuerza la separación Iglesia-Estado, argumentos que habían sido populares entre los años 50 y 60, pero que ahora se habían debilitado en las discusiones del partido liberal ${ }^{49}$ Sin embargo, los gobiernistas sí usaron el argumento de que el conservatismo había defendido tradicionalmente un orden respaldado por la religión y la Iglesia católica, y que los ejércitos del gobierno tenían por ello una protección de orden trascendente. La exaltación de la religiosidad de los generales, la consagración de los ejércitos a las múltiples advocaciones de la Virgen, la realización de misas antes de los combates, la celebraciones del Te Deum después de los triunfos y especialmente la consagración oficial de Colombia en 1902 al Sagrado Corazón de Jesús (figura representativa de la contrarrevolución de la Vandée, cuyo culto fue promovido en el papado de Pío IX) ${ }^{50}$ fueron acciones que buscaban legitimidad y apoyo a la causa gobiernista. ${ }^{51} \mathrm{Al}$ mismo tiempo, el partido rebelde era descalificado por haber intentado debilitar históricamente el poder de la Iglesia en el pasado. Algunos miembros del alto clero promovieron incluso un rechazo radical a toda idea liberal, aduciendo argumentos históricos y citando textos papales. Desde su interpretación, era necesario inscribir la pugna local de liberales contra conservadores dentro de una lucha de alcances globales

en diversas poblaciones del territorio. Baillie Dunlap, Rafael Uribe Uribe, pp. $130-133$.

${ }^{49}$ Como observa Vincent Baillie, la Convención del partido liberal en 1897 elaboró un listado de propuestas de reforma política que, aunque apuntaba a la disminución del poder presidencial y a garantizar derechos individuales, mostraba una aceptación tácita de la Constitución de 1886 y un paso al costado en la discusión tradicional contra la Iglesia. Baillie Dunlap, Rafael Uribe Uribe, p. 119.

50 Sobre los usos políticos de la figura del Sagrado Corazón de Jesús ver: Cecilia Henríquez de Hernández, "El Sagrado Corazón en la historia de Colombia": Revista de la Universidad Nacional, 22 (1989), pp. 80-88.

51 A las manifestaciones de esa religiosidad se refiere Laura Paola Ávila, Ante el dolor de los demás. Experiencias de sufrimiento en las ambulancias de la guerra de los Mil Días, Bogotá: Universidad de los Andes, 2019 (Tesis de doctorado en Historia), pp. 168-181 
emprendida por la Iglesia católica contra la expansión de ideas liberales que se había vivido a nivel mundial durante todo el siglo y que ponía en peligro su tradicional hegemonía. ${ }^{52}$ La influencia de este tipo de polarizaciones discursivas es innegable, aunque seguramente dependió de la influencia que tuvieran los párrocos en las poblaciones. ${ }^{53}$

Ahora bien, al enfatizar en lo discursivo, se dejan de lado los aspectos pragmáticos de la acción guerrera propiamente dicha. En esta última parte se habla sobre cómo en la guerra misma se tomaban decisiones obligadas por las vicisitudes de la guerra, y bastante alejadas de la discusión ideológica y partidista. ${ }^{54}$ Habría que empezar por el punto de que la mayoría de los ejércitos, tanto gobiernistas como rebeldes, se conformaron, no por el poder persuasivo de los discursos, ni por las convicciones políticas de sus miembros, sino por el mero uso de la

52 Sobre sacerdotes y obispos que asumieron una posición abiertamente antiliberal e incluso llamaron a la toma de las armas de sus feligreses contra los rebeldes, se ha escrito ampliamente. Ver por ejemplo Fernán González, Poderes enfrentados, pp. 260-269; Jaramillo, Los guerrilleros, pp. 306-331; Aída Martínez Carreño, La guerra de los Mil Días. Testimonios de sus protagonistas, Bogotá: Planeta, 1999, pp. 140-148.

53 Es indicativo de la efectividad de las campañas de satanización extrema del liberalismo el hecho de que Uribe Uribe en 1912 se sintiera obligado a escribir su exhaustivo texto, De cómo el liberalismo político colombiano no es pecado, Bogotá: Casa Editorial de 'El Liberal', 1912, revisando y refutando uno a uno los argumentos aducidos para descalificar la doctrina liberal como anticristiana. Al respecto indica que su escrito lo hizo para proteger a los liberales que, especialmente en ámbitos rurales, eran acosados por su adscripción.

54 Esta parte del artículo toma ideas desarrolladas en Brenda Escobar, De los conflictos locales a la guerra civil. Tolima a finales del siglo XIX, Bogotá: Academia Colombiana de Historia, 2013, capítulo 4. Esta investigación se basa en el análisis de la dinámica de la guerra en poblaciones específicas del departamento del Tolima, especialmente aquellos donde hubo fuerte dominio de guerrillas liberales. Este trabajo intentó incluir en la reflexión el tema de la organización política de actores rurales y de la acción política subalterna, pero encontró que los aspectos de orden pragmático en torno a la supervivencia se constituyeron en móviles centrales de la acción de estos grupos armados rurales. Para comprender la dinámica de la conformación de fuerzas liberales de carácter popular sigue siendo muy interesante el ensayo en Malcolm Deas, Del poder y la gramática, pp. 121-173. 
fuerza. Se conocen bien los mecanismos de los ejércitos gobiernistas. ${ }^{55}$ Se hacían encierros en plazas públicas y eran tomados por la fuerza todos los hombres que resultaran capturados, incluyendo a niños o personas con impedimentos físicos o muy mayores. El gobierno era consciente de la impopularidad y aun peligro de estos ejércitos conformados por personas sin ningún compromiso con la causa, más alertas a la deserción que a la acción guerrera. Por ello, las órdenes que se hacían de reclutamiento iban acompañadas de advertencias sobre la discreción con que debían llevarse a cabo, como esta de un jefe militar de Bogotá al alcalde de Ibagué, capital del departamento del Tolima: "Creo conveniente que por ahora no debe reclutarse en el centro de la ciudad para no alarmar". En otro momento de la guerra se le exigió al alcalde de esa misma población organizar trescientos conscriptos "tomándolos de los campos y alrededores de la ciudad y procurando que sean hombres bien constituidos y robustos en lo posible, solteros y amigos del gobierno [...] [obrando] con circunspección y reserva." 56

Arbitrariedades cometidas por el gobierno en estas levas fueron denunciadas por administradores de minas de origen inglés que explotaban oro y plata en cercanías a la población de Mariquita, también en Tolima. Uno de ellos describía un reclutamiento llevado a cabo en las minas en el que los agentes del gobierno entraron de noche y por sorpresa a las instalaciones de las minas. Reclutaron a todo el que encontraron, incluso sacándolos de sus casas y disparando contra aquellos que intentaron escapar. Los reclutadores también habían robado gallinas y ropa de las casas de los peones. El administrador inglés indicaba que ellos habían pagado por los salvoconductos de estos trabajadores, que no fueron respetados. A esto se unía el hecho de que

\footnotetext{
55 Sobre esto por ejemplo: Tirado, Aspectos sociales, pp. 265-308; Jaramillo, Los guerrilleros, pp. 215-218; Juan Carlos Jurado, "Soldados, pobres y reclutas en las guerras civiles colombianas": Revista de Indias, 64:232 (2004), pp. 673-696. En el reciente libro de Peter Guardino sobre la guerra entre México y Estados Unidos, pueden observarse similitudes con el reclutamiento en México de mediados del siglo XIX: Peter Guardino, La marcha fúnebre. Una historia de la guerra entre México y Estados Unidos, México: Grano de Sal, 2018, p. 116.

56 Archivo Histórico de Ibagué - Alcaldía (en adelante AHI-A), caja 321, folio 231; caja 341 , folio 416 respectivamente.
} 
los reclutadores eran antiguos trabajadores de las minas que habían sido despedidos. Así, lo personal y lo político se entremezclaba. ${ }^{57}$

Pero los grupos armados rebeldes también tuvieron que recurrir a la fuerza para conformar sus filas, pues el carisma de los líderes y el espíritu de rebeldía reinante en algunas poblaciones no eran suficientes para formar ejércitos rebeldes sólidos y mantenerlos por un tiempo prolongado. Las memorias de quienes participaron en la guerra suelen hablar del entusiasmo que rodeaba a partidarios comprometidos en un mundo en el que hacer la guerra era parte de las actividades que debía saber desempeñar un caballero. ${ }^{58}$ Ese entusiasmo se formaba con los discursos exaltados de líderes del partido como Uribe Uribe, quien como decíamos, generó un fuerte fervor hacia la opción guerrera que logró trasmitir en muy diversas regiones. Pero también por las actividades de organización de la oposición armada. Esto se observa por ejemplo en la correspondencia del mismo Uribe en el tiempo anterior a la guerra, en que se encuentran cartas de adeptos que decían estar listos para entrar en acción y rendir la vida por el partido. 59

No obstante, cuando llegó la fecha señalada para iniciar la guerra, de aquellos entusiastas solo pocos se enlistaron. Es diciente al respecto un relato de un liberal comprometido. Se encontraba en la población de

57 Public Record Office 135/254-197863, vicecónsul inglés en Honda (John Gillies) a cónsul inglés en Bogotá (George E. Welby), 19/01/1900; 135/255-197863, administrador de minas, Thomas Sharman, a cónsul Welby, 07/02/1900.

58 Sobre este tema ver Michael Riekenberg, Gewaltsegmente. Über einen Ausschnitt der Gewalt in Lateinamerika, Leipzig: Universitätsverlag, 2003, pp. 57-58. Un análisis del género de las memorias de combatientes en esta guerra se encuentra en: Brenda Escobar, "La guerra de los Mil Días vista a través de las memorias": Luis Javier Ortiz (ed), Ganarse el cielo defendiendo la religión. Guerras civiles en Colombia, 1840-1902, Medellín: Universidad Nacional de Colombia, 2005, pp. 465-480. También Malcolm Deas, "Las memorias de los generales. Apuntes para una historiografía de la guerra": Sánchez / Aguilera (eds.), Memoria de un país en guerra, pp. 125-141.

${ }^{59}$ La red epistolar de Uribe llegaba hasta remotos pueblos de la geografía nacional. En los años anteriores a la guerra se observa una activa correspondencia en que sus remitentes comentaban cómo se recibían y se difundían los discursos de El Autonomista y manifestaban la adhesión a la causa guerrera. Todo el archivo epistolar de Uribe se encuentra en el Archivo General de la Nación, Fondo Academia Colombiana de Historia, Rafael Uribe Uribe. Para estas adhesiones ver por ejemplo documentos de 1898 en caja 5, folios 2129-2131, 2224, 2351-2354, 2382-2390v. 
Guamo (Tolima), donde tuvo la intención de tomarse la guarnición militar del gobierno. Pero no le fue posible reunir gente para tomar las armas y parque existentes. Antes de que lo reclutara el gobierno, se dirigió a la población de Chaparral, de tendencia liberal, a reunir más apoyo. Allí había 80 personas en listas organizadas por los notables liberales. Pero solo se reunieron trece. Con esos trece hombres no se pudo hacer el ataque a Guamo. Así razona el relator:

"Si ese parque [del Guamo] se hubiera tomado [...] se hubieran armado inmediatamente lo menos 800 hombres, base más que suficiente para apoderarse del Tolima, que estaba con muy escasa fuerza veterana y donde el Gobierno, por los abusos y errores cometidos, estaba perfectamente desacreditado". 60

El relato habla de los muchos entusiastas y los pocos decididos. Pero también de las primeras acciones, dirigidas principalmente a aprovechar la sorpresa para tomar las armas de guarniciones mal protegidas. Y de la manera desinformada como se asumía que el triunfo de los rebeldes no solo era posible, sino también inminente, bajo el supuesto de que el gobierno gozaba de poca legitimidad.

Algunas de esas primeras tomas de guarniciones generaron enfrentamientos encarnizados. $\mathrm{Y}$ los primeros muertos. Esas impresiones bajaban los ánimos. Ya no se trataba de aventuras arriesgadas de jóvenes, sino de enfrentar el peligro de perder la vida. Muchos jóvenes, animados pero bisoños, murieron en esas primeras acciones que causaron ingrata impresión, pues eran jóvenes de familias reconocidas en sus pueblos.

Ya pasada la acción de sorpresa inicial, el sueño de tumbar al gobierno de un plumazo por su supuesta debilidad dio paso a una guerra de verdad. Para ello había que tener financiamiento. Este se esperaba de los líderes nacionales, quienes tenían sus propios frentes de guerra y no tuvieron el apoyo en armas esperado de gobiernos amigos, como se indicó antes. Había que recurrir a la financiación local. Esta pudo llegar en principio de hacendados dispuestos a colaborar con los rebeldes, un tanto por afinidad ideológica y un tanto por defenderse de exacciones del gobierno (reclutamiento de peones, impuestos de guerra, expropiación de tierras, haciendas, ganado o cultivos). Ya en el transcurso de la guerra, los rebeldes adquirieron una dinámica propia

${ }^{60}$ La guerra en el Tolima, p. 106. 
con mecanismos de financiación que podían empezar con aportes voluntarios pero pasaban rápidamente a las exacciones por la fuerza.

Un joven agricultor que participó en una guerrilla liberal que se estableció entre 1900 y 1902 cerca de Ibagué, describía así el modo de financiación de esa guerrilla:

"Nos decían: 'Todo el que sea amigo de la libertad tiene que servir por la fuerza, o dar cincuenta pesos mensuales hasta que se acabe la guerra. Todos los hombres, de doce años para arriba, hasta sesenta, tienen que servir'".

Los hacendados debían entregar altas sumas de dinero y ganado como "impuesto de guerra". Quienes no pagaban, recibían intimidaciones y fuertes castigos:

“[Ramón] Chaves [el jefe] echaba un comparto [orden de pago en especie], como una res, dos marranos, cincuenta pesos, y si no lo pagaban al momento, les sacaba el doble, o mandaba que arriaran lo que toparan y les daba palo a los que cogía, al hijo o al que cogiera de la familia".

De ese modo, esta guerrilla adquirió una dinámica económica autónoma, basada en impuestos de guerra, expropiaciones, cobro de peajes, combinado con la explotación agrícola y el comercio de ganado. En el mismo testimonio se manifestaba: "no les faltaban gallinas, piscos, queso, mantequilla, marranos, novillas, bestias y dinero". Y más adelante, refiriéndose al jefe Ramón Chaves:

“constantemente manda ganado y novillonas gordas para los lados del páramo [...]. Vi pasar varias reses de él [...] no sé si será que lo ha comprado [el ganado] o que lo ha quitado".

Ello llevaba al enriquecimiento, así fuera momentáneo y correspondiente a la cultura material campesina:

"no me pareció pobre el general Chaves; tiene doce bestias muy bonitas, y un caballo rucio, ancho, gordo, grande y muy hermoso; tiene muy buen galápago, nuevecito, buen revólver, un carriel [cartera] nuevecito de llaves, taquiao [lleno] de billetes" ${ }^{61}$

El comportamiento de esta guerrilla puede resultar indicativo de la deriva que fue tomando la guerra a medida que se fue extendiendo en el territorio y prolongando en el tiempo. Si bien la guerra en principio había sido impulsada por medio de discursos cargados de contenido

61 Extractos de testimonios de 1901 de testigos de las acciones guerrilleras en immediaciones del municipio de Ibagué: AHI-A, caja 321, folios 675, 677v. 
político, los que eran fieles a la causa no eran tantos y la propia guerra los iba amedrentando. En cambio, iban entrando personas que eran conminadas a participar a la fuerza, no porque se sintieran comprometidas con un partido o una ideología. ${ }^{62}$

De este modo, la guerra fue alcanzando dimensiones inmanejables, comandada por una serie de grupos sin cohesión pero con poder local, que ampliaban o disminuían su número según las necesidades, ${ }^{63}$ pero que lograron mantener en territorios específicos una autonomía económica y un monopolio de la violencia. Los habitantes de esas regiones no tenían mucho espacio de acción: obedecían al bando que ejerciera hegemónicamente su poder.

De esta manera, a pesar de que la guerra inició por el malestar con el sistema electoral y las quejas por el bloqueo de la participación política de aquellos que podían votar, en su prolongación fue envolviendo a un número cada vez más amplio de personas y cubriendo diferentes regiones del país. Para explicar esa expansión de la guerra confluyen diversas razones. Hubo innegablemente una organización previa, planeación de estrategias, conteo de hombres comprometidos, gestiones para la consecución de armas. La organización no solo se centró en el movimiento principal que se realizaría en el departamento de Santander (al nordeste del país, en límites con Venezuela), sino también en lugares distantes a ese centro como la frontera con Ecuador la Guajira o el Tolima. Se pintaba un panorama triunfalista, a partir de la premisa de que el gobierno estaba debilitado y dividido en facciones,

62 Stathis Kalyvas se basa en un amplio trabajo de campo estudiando la guerra civil griega de los años 1946-1950 para mostrar su tesis de que la violencia, la coerción o el dominio territorial, más que la preferencia por una ideología o a un bando, son los factores que más influencia tienen para explicar la integración de personas a uno u otro bando en una guerra civil. Tal explicación resulta acorde también para entender la conformación de estos grupos de rebeldes liberales que analizados aquí. Kalyvas, The Logic of Violence, especialmente pp. 91-104.

63 Ante la inminencia de combates, también estas fuerzas hacían reclutamiento forzoso. Se encuentran no pocos relatos de participantes que dijeron que habían entrado a grupos en armas de manera forzada, a semejanza de como se describía la conscripción realizada por gobiernistas: hombres que se encontraban en el mercado, en las casas o en fincas aledañas a centros poblados eran encerrados a la fuerza. Los reclutas eran luego enviados al combate, muchas veces sin darles ningún tipo de munición. Ver por ejemplo AHI-A, caja 321, folios 301-311; 351-353; caja 337, folios 247-254. 
y encabezado por un presidente y un vicepresidente de edades muy avanzadas. Igualmente se confiaba en el apoyo en armas que se recibiría de gobiernos amigos de Ecuador, Venezuela y Nicaragua. Las acciones que debían realizarse en un principio se veían también como alcanzables: toma de armamento de cuarteles mal protegidos, destrucción de líneas de telégrafo, apoyo de una población descontenta con el gobierno. Mientras tanto, el ejército liberal haría combates formales en el centro intentando tomarse la capital. El triunfo no se veía lejano.

Había también una innegable identificación de muchas personas con su partido. Había localidades que se reconocían de tendencia liberal o conservadora, tradición que obedecía a su historia (pueblos fundados bajo determinado régimen, el poder del párroco local, experiencia de guerras pasadas, tierra natal de un líder político). Pero también historias familiares: muertos a vengar, peleas casadas, etc.

$Y$ es insoslayable el provecho que algunos podrían sacar haciéndose parte de los grupos rebeldes, pues se abría la posibilidad de no tener que ir a padecer los rigores del ejército. En cambio, unirse a los rebeldes podía ser visto en principio como una labor menos dura que pertenecer a ejércitos, puesto que se trataba de cometer actos de sabotaje y entorpecimiento del control estatal, no de emprender enfrentamientos a campo abierto como lo requería la estrategia de la guerra regular.

La guerra fue una al momento de proponerla y otra en su desarrollo. Se planteaba como una guerra rápida pero, en la práctica, el ejército liberal sufrió derrotas muy fuertes desde el comienzo y no había pasado un año cuando ya había sido derrotado el ejército mejor organizado de los liberales en el centro de operaciones, Santander. Aun con ello, sus líderes siguieron impulsando desde el extranjero la consecución de armas y la organización de nuevos ejércitos. Por su parte, las guerrillas también adquirieron una dinámica propia. Como se vio, de grupos de sabotaje pasaron a ser fuerzas con financiación propia, armas y un poder local que ponía en entredicho el poder estatal, o que ejercía hegemonía en zonas de débil o nula presencia estatal. La dinámica guerrera les daba nuevas vías de acción a estos grupos y aunque tenían dificultades para hacer alianzas supralocales, fueron efectivos para generar empoderamiento local. Así, las causas trascendentes de la rebelión tenían poca validez para estos grupos. Estos actuaban sin tener 
en cuenta las directrices de los líderes del partido rebelde, mucho menos estando estos exiliados.

Esto hizo que la guerra se prolongara sin un mando medianamente centralizado y ante la mirada desesperada de los liberales citadinos, y aun de los gestores de la guerra, como Uribe Uribe, que buscaban darle fin a una situación de guerra que ellos ya no dominaban. De esta situación, es diciente que en 1901, desde Nueva York, Uribe Uribe deslegitimara la lucha que seguían llevando dirigentes populares en distintas zonas del país, a los que él mismo había instigado a hacer la guerra. ${ }^{64}$ Otros intentos de organizar el ejército liberal desde la dirigencia del partido, teniendo como base el departamento de Panamá, tuvieron un cierto éxito militar pero no llegaron a obtener el anhelado triunfo sobre el gobierno, dada la incidencia que Estados Unidos ejercía en ese departamento y su apoyó al orden gobiernista. ${ }^{65}$ Fue por su intervención que se dio cierre oficial a la guerra en noviembre de 1902, pero también fue esa incidencia creciente, en contraposición a la crisis política que dejó la guerra, la que le permitió a Estados Unidos "tomarse" Panamá un año después.

\section{Conclusión}

En las guerras civiles del XIX confluyeron variados factores que las generaron y las prolongaron. Podría decirse, en términos generales, que el estado colombiano en formación en el siglo XIX tuvo dificultades para gozar de legitimidad más allá de unas cuantas zonas. Esto hacía que las medidas del gobierno fueran vistas como impuestas y no era difícil que generaran descontento e incluso oposición armada. Ello también en medio de una idea compartida de la política como un ámbito de integración de copartidarios y exclusión de contrarios. Los que resultaban excluidos declaraban como legítima y como única la vía de la guerra para acceder al poder. Esta era vista como una forma de hacer política, aunque esta percepción iba cayendo en desprestigio a finales de siglo y en el caso colombiano, con la afrenta vivida por la pérdida de

64 Rafael Uribe Uribe, "A los liberales de Colombia", Nueva York, 1901, en: Documentos militares, pp. 179-185.

65 Sobre los acontecimientos de la guerra en el departamento de Panamá y la importante organización militar liberal que organizó allí el líder liberal Benjamín Herrera, ver Lucas Caballero, Memorias de la guerra, capítulos 11 a 22. 
Panamá, tras la guerra de los Mil Días, se volvió una forma de acción indefendible. 66

La defensa de prácticas electorales fiables e incluyentes, base de la existencia de un régimen republicano viable, hacía parte de las motivaciones siempre al alcance para llamar a nuevos levantamientos contra gobiernos que no lograban una legitimidad mínima. El discurso exaltado pintaba las acciones del gobierno como propias de un régimen dictatorial intolerable, solo superable por medio de la rebelión armada. Innegablemente esos llamamientos a la guerra generaban adeptos. Pero para entender la prolongación de este conflicto, debe dársele valor también a aspectos de orden menos político, no porque la gente del común careciera de convicciones, sino porque los peligros de la guerra no dejaban mucho tiempo para la discusión ideológica. El asunto de mantenerse vivo en medio de un ambiente de zozobra y amenaza de muerte permanentes seguramente hizo parte de la decisión de muchos de tomar las armas por uno u otro bando. Estos aspectos de orden más pragmático deberían seguir siendo explorados y dárseles más preponderancia.

66 Sobre este cambio de percepción del fenómeno de la guerra como acción política legítima ver Isidro Vanegas, "Lo inevitable y lo fortuito de la violencia política. El liberalismo y la guerra de los Mil Días”: Memoria y Sociedad, 20: 40 (2016), pp. 152-168. 